\title{
Prevalence and associated factors of visually impaired cataract of the better eye among adults aged 40 years and above in Mahara Medical Officer of Health Area, Sri Lanka: a cross-sectional study
}

\author{
Champa Hapugoda ${ }^{1}$ \& Chrishantha Abeysena $^{2 *}$ \\ ${ }^{1}$ Ministry of Health, Sri Lanka; ${ }^{2}$ Department of Public Health, Faculty of Medicine, University of Kelaniya, Sri Lanka \\ *Correspondence: chrishanthaabeysena@yahoo.com
}

DOI: https://doi.org/10.4038/jccpsl.v25i1.8162

Received on: 27 June 2018

Accepted on: 09 February 2019

\begin{abstract}
Introduction: Cataract is the main cause of visual impairment in the world, accounting for $51 \%$ of global blindness.

Objectives: To determine the prevalence and associated factors of visually impaired cataract of the better eye among adults aged 40 years and above in Mahara Medical Officer of Health (MOH) Area in Sri Lanka

Methods: This was a community-based descriptive cross-sectional study conducted in an MOH area during the period August-October 2009. The study population consisted of 602 adults aged 40 years and above selected using cluster sampling technique. Study instruments were interviewer-administered questionnaire and a record sheet. The presence of lens opacities following ophthalmoscope examination with visual acuity less than 6/18 in the better eye was considered as cataract. Multivariate logistic regression was applied for assessment of factors associated with cataract. Results were expressed as adjusted odds ratio (aOR) and 95\% confidence interval (CI).

Results: The overall prevalence of visually impaired cataract of the better eye was $14.6 \%(95 \% \mathrm{CI}=11.78,17.42)$. It was $35.1 \%(95 \% \mathrm{CI}=28.3,41.86)$ among the age group of 60 years and above and $15 \%(95 \% \mathrm{CI}=11.28,18.72)$ among females and $14.4 \%(95 \% \mathrm{CI}=9.77,18.43)$ among males. After controlling confounding factors, age 60 years and above $(\mathrm{aOR}=4.72 ; 95 \% \mathrm{CI}=3.18,7.01)$, lower level of education $(\mathrm{aOR}=2.01 ; 95 \% \mathrm{CI}=1.39,2.89)$ and duration of diabetes mellitus of more than six years $(\mathrm{aOR}=2.13 ; 95 \% \mathrm{CI}=1.11,4.07)$ were found to be the associated factors.

Conclusions: The burden due to prevalence of visually impaired cataract in the better eye was considered serious as it will affect the quality of life. Being elderly, lower education and longer duration of diabetes mellitus were associated with visually impaired cataract.
\end{abstract}

Key words: blind, cataract, factors, prevalence, vision 


\section{Introduction}

Cataract has been defined as any opacity in the crystalline lens, but the use of term implies that the opacities are clinically significant (1). One of the main causes of visual impairment in the world is cataract (2) while $51 \%$ of global blindness is due to cataract (3). Prevalence of cataract in the age group above 60 years in the Gampaha district was 56\% in 2006 (4). Edussuriya et al reported that $79 \%$ of visual impairment was due to cataract in the population aged $\geq 40$ years (5).

According to population projections, there will be $43 \%$ of over 40 years of age in 2021 (6). While the principle non-modifiable risk factor for cataract is ageing, other frequently associated risk factors are certain eye diseases, diabetes, hypertension, ultraviolet irradiation and smoking (7). Visually disabling cataract was found to occur far more frequently in developing countries than in industrialized countries (8). World Health Organisation has introduced rapid assessment of avoidable blindness which defines cataract as lens opacities with visual acuity of $<6 / 18$ (9).

In implementing preventive programmes, it is necessary to address factors associated with cataract. There is epidemiological transition taking place in parallel to demographic transition. There are changes in socio-economic status, diet, physical activity, alcohol, tobacco use and presence of chronic diseases like diabetes mellitus and hypertension. Evaluation of association between cataract and the above factors will be helpful in preventive measures. Therefore, the objective of this study was to determine the prevalence of visually impaired cataract of the better eye and associated factors among adults aged forty years and above in Mahara MOH Area.

\section{Methods}

This was a community-based descriptive crosssectional study conducted in Mahara $\mathrm{MOH}$ Area during the period August-October 2009. The study population consisted of adults aged 40 years or above by 1 st July 2009 . All the males and females who were residing in this area for at least six months were included. Exclusion criteria were people who were bedridden or hospitalized.

For the calculation of sample size, we considered the desired prevalence of cataract as $20 \%$, precision as $5 \%$ with $95 \%$ confidence limits, design effect as
1.5 and non-response rate as $10 \%$. Therefore, the final sample size was 634 . A cluster sampling method was used, in which a public health midwife (PHM) area was considered as a cluster. Of the 44 PHM areas in the selected $\mathrm{MOH}$ area, $16 \mathrm{PHM}$ areas were selected by simple random sampling. In each selected PHM area, a road was selected randomly. First house of the road was the index house. The direction was to the left by standing at the front door facing outside from the index house. Forty houses were selected from each PHM area and one eligible adult from each house.

An interviewer-administered questionnaire was used for collecting demographic characteristics of the person, socio-economic status, presence of diabetes mellitus, presence of hypertension and other behaviours. Both open-ended and close-ended questions were used. The content validity was maintained by reviewing literature and the questionnaire evaluated by an ophthalmologist beforehand. Age was crosschecked with national identity card. History of diabetes mellitus and hypertension was cross-checked with clinic card or diagnosis card when available.

A record sheet was used to record the presence of cataract. Cataract was detected by using an ophthalmoscope. A darker area in the selected house was prepared for ophthalmoscope examination. The ophthalmoscope was adjusted so that the light was not brighter than required. The aperture was adjusted to a plain white circle. The dioptre dial was set to zero. The left hand and the left eye were used to check the participant's left eye. The right hand and the right eye were used to check the right eye of the participant. Examiner's free hand was placed on the shoulder of the participant to stabilize the person. The participant was asked to stare at a distant fixed point parallel to examiner's ear. The ophthalmoscope was kept close to examiner's eye. The examiner looked through the ophthalmoscope and shined a light into the participant's eye from about two feet away. The examiner could see the retina as a 'red reflex' where there is no obliterating opacity or no cataract. Lens opacities could be seen if present. With mature cataract, there is no red reflex seen (7). Ophthalmoscope was checked each day before starting the examination. Visual acuity was tested using a Snellen's chart under good day-light at seated position. Cataract was defined as presence of lens opacity with ophthalmoscope examination. Both eyes were tested. Presence of lens opacities with visual acuity of <6/18 (9) of the better eye (10) was considered as 'visually impaired cataract'. 
A pre-test was done in Gampaha MOH Area, where 20 adults participated. A few changes were made accordingly to the questionnaire and record sheet. Two medical students were trained for administering the interviewer-administered questionnaire. The ophthalmoscope examinations were done by the first author. The participants who had visual problems were referred to the District General Hospital Gampaha.

\section{Data analysis}

Data analysis was done using Statistical Package for Social Sciences (SPSS) version 16. Multiple logistic regression with backward selection was applied for assessment of the factors associated with cataract. Results were expressed as adjusted odds ratio (aOR) and their corresponding 95\% confidence intervals (CI).

\section{Results}

A total of 640 participants was invited, of which 602 participated, giving a non-response rate of $5.9 \%$. The median age of the study population was 53 years (range 40-90 years) and 191 (33.7\%) of them were 60 years and above. Among the study population, 468 (77.8\%) were educated above grade five. It was found that a majority was engaged in non-paid employment $(\mathrm{n}=331 ; 55 \%)$. Of the total study population, 267 $(44.4 \%)$ had cataract in either eye or both.

The prevalence of visually impaired cataract of the better eye was $14.6 \%(95 \% \mathrm{CI}=11.78,17.42)$ among the study population. The prevalence of cataract in population aged $\geq 60$ years was higher $(35.1 \% ; 95 \%$ $\mathrm{CI}=28.34,41.86)$ than that in $40-59$ aged $(5.1 \%$; $95 \%$ $\mathrm{CI}=2.98,7.22)$ population. The prevalence of cataract in males was $14.1 \%(95 \% \mathrm{CI}=9.77,18.43)$ and $15 \%$ $(95 \% \mathrm{CI}=11.28,18.72)$ in females.

There were statistically significant associations between visually impaired cataract and age of 60 years and above, lower level of education and lower monthly per capita income (Table 1). There were statistically significant associations between cataract and history of alcohol consumption of more than 20 years and of smoking more than 20 years (Table 2).

After controlling for confounding effects, age 60 years and above $(\mathrm{aOR}=4.72 ; 95 \% \mathrm{CI}=3.18,7.01)$, lower level of education $(\mathrm{aOR}=2.01 ; 95 \% \mathrm{CI}=1.39$, 2.89) and duration of diabetes mellitus of more than six years $(\mathrm{aOR}=2.13 ; 95 \% \mathrm{CI}: 1.11,4.07)$ showed statistically significant association with visually impaired cataract of the better eye (Table 3 ).

Table 1. Distribution of the study sample by cataract and socio-economic factors

\begin{tabular}{|c|c|c|c|c|c|}
\hline \multirow{3}{*}{ Socio-economic factors } & \multicolumn{4}{|c|}{ Presence of cataract } & \multirow{3}{*}{ OR $(95 \%$ CI $)$} \\
\hline & \multicolumn{2}{|c|}{ Yes $(n=88)$} & \multicolumn{2}{|c|}{ No $(n=514)$} & \\
\hline & No. & $\%$ & No. & $\%$ & \\
\hline \multicolumn{6}{|l|}{ Age in years } \\
\hline$\geq 60$ & 67 & 76.1 & 124 & 24.1 & $10.04(5.91-17.06)$ \\
\hline $40-59$ & 21 & 23.9 & 390 & 75.9 & \\
\hline \multicolumn{6}{|l|}{ Sex } \\
\hline Female & 53 & 60.2 & 301 & 58.6 & $1.07(0.68-1.70)$ \\
\hline Male & 35 & 39.8 & 213 & 41.4 & \\
\hline \multicolumn{6}{|l|}{ Educational level } \\
\hline Up to grade 9 & 69 & 78.4 & 273 & 53.1 & $3.21(1.86-5.48)$ \\
\hline Above grade 9 & 19 & 21.6 & 241 & 49.9 & \\
\hline \multicolumn{6}{|l|}{ Monthly income Rs. } \\
\hline Less than 2500 & 56 & 69.1 & 244 & 51.2 & $2.14(1.29-3.52)$ \\
\hline$\geq 2500$ & 25 & 30.9 & 233 & 48.8 & \\
\hline \multicolumn{6}{|l|}{ Employment } \\
\hline Non-paid & 56 & 63.6 & 275 & 53.5 & $0.67(0.41-1.05)$ \\
\hline Paid & 32 & 36.4 & 239 & 46.5 & \\
\hline
\end{tabular}


Table 2. Distribution of the study sample by status of cataract, other diseases and behavioural factors

\begin{tabular}{|c|c|c|c|c|c|}
\hline \multirow{3}{*}{$\begin{array}{l}\text { Diseases and behavioural } \\
\text { factors }\end{array}$} & \multicolumn{4}{|c|}{ Presence of cataract } & \multirow{3}{*}{ OR $(95 \% \mathrm{CI})$} \\
\hline & \multicolumn{2}{|c|}{ Yes $(n=88)$} & \multicolumn{2}{|c|}{ Yes $(n=88)$} & \\
\hline & No. & $\%$ & No. & $\%$ & \\
\hline \multicolumn{6}{|l|}{ History of diabetes } \\
\hline Present & 23 & 26.1 & 99 & 19.3 & $1.48(0.88-2.50)$ \\
\hline Absent & 65 & 73.9 & 415 & 80.7 & \\
\hline \multicolumn{6}{|l|}{ Duration of diabetes } \\
\hline$>6$ years & 13 & 14.8 & 44 & 8.6 & $1.85(0.95-3.60)$ \\
\hline$\leq 6$ years & 75 & 85.2 & 470 & 91.4 & \\
\hline \multicolumn{6}{|l|}{ History of hypertension } \\
\hline Present & 28 & 31.8 & 117 & 22.8 & $1.58(0.97-2.59)$ \\
\hline Absent & 60 & 68.2 & 397 & 77.2 & \\
\hline \multicolumn{6}{|l|}{ Duration of hypertension } \\
\hline$>6$ years & 14 & 15.9 & 64 & 12.5 & $1.33(0.71-2.49)$ \\
\hline$\leq 6$ years & 74 & 84.1 & 450 & 87.5 & \\
\hline \multicolumn{6}{|l|}{ Alcohol consumption } \\
\hline No & 26 & 29.5 & 166 & 32.3 & $0.88(0.54-1.44)$ \\
\hline Yes & 62 & 70.5 & 348 & 67.7 & \\
\hline \multicolumn{6}{|c|}{ Duration of alcohol consumption } \\
\hline$>20$ years & 17 & 19.3 & 43 & 8.4 & $2.62(1.42-4.85)$ \\
\hline$\leq 20$ years & 71 & 80.7 & 471 & 91.6 & \\
\hline \multicolumn{6}{|l|}{ Smoking status } \\
\hline Smoker & 22 & 25.0 & 121 & 23.6 & $1.08(0.64-1.82)$ \\
\hline Non-smoker & 66 & 75.0 & 393 & 76.4 & \\
\hline \multicolumn{6}{|l|}{ No. of cigarettes smoked } \\
\hline$>3$ per day & 9 & 10.2 & 69 & 13.4 & $0.73(0.35-1.53)$ \\
\hline$\leq 3$ per day & 79 & 89.8 & 445 & 86.6 & \\
\hline \multicolumn{6}{|l|}{ Duration of smoking } \\
\hline$>20$ years & 12 & 13.6 & 32 & 6.2 & $2.38(1.17-4.82)$ \\
\hline$\leq 20$ years & 76 & 88.4 & 482 & 93.8 & \\
\hline
\end{tabular}


Table 3. Adjusted odds ratios of the factors associated with cataract

\begin{tabular}{lccccc}
\hline Variable & $\begin{array}{c}\boldsymbol{\beta} \\
\text { co-efficient }\end{array}$ & $\begin{array}{c}\text { Standard } \\
\text { error }\end{array}$ & AOR & 95\% CI & p value \\
\hline Educational level: up to Grade 9 & 0.69 & 0.19 & 2.01 & $1.39-2.89$ & $<0.001$ \\
Duration of Diabetes Mellitus $>6$ years & 0.75 & 0.33 & 2.13 & $1.11-4.07$ & 0.02 \\
Age $\geq 60$ years & 1.55 & 0.20 & 4.72 & $3.18-7.01$ & $<0.001$ \\
\hline
\end{tabular}

$\mathrm{aOR}=$ adjusted odds ratio; $\mathrm{CI}=$ confidence interval

\section{Discussion}

The overall prevalence of visually impaired cataract of the better eye was $14.6 \%$. The prevalence of cataract in those aged 60 years and above was $35.1 \%$. The prevalence of cataract in females and males was $15 \%$ and $14.4 \%$, respectively. Several studies reported higher prevalence than our study. Nanayakkara (2006) had reported that the prevalence of cataract in elderly was $56 \%$ (4). In the same study, more prevalence among females $(65.3 \%)$ than males $(48.2 \%)$ was reported. The study however had not defined cataract in relation to visual acuity. This could be explained by the difference in definitions of the two studies where the definition is narrower in our study. Another community-based study done in Bangladesh reported that the prevalence was $8.4 \%$ for the 50 years and above age category (9). This study defined cataract in relation to visual acuity of less than $6 / 18$, as in our study. A study in Singapore reported that the prevalence of visually significant cataract in either eye was $6.54 \%$ according to the Wisconsin Grading System (11). In a study done in Andra Pradesh (12), the overall prevalence of cataract was $3.2 \%$ while it was reported in the age group $40-49$ years as $0.88 \%, 50-59$-year age group as $33.5 \%, 60-69$-year age group as $24.32 \%$ and above 70 -year age group as $30 \%$ (12). According to a study done in India (13) the prevalence of cataract among the population of more than 50 years of age was $62.8 \%$ and among males and females, it was $66.9 \%$ and $60.4 \%$, respectively. A study in Korea (14) also reported that the prevalence was $25.2 \%$ in the $40-64-$ year age group and $87.8 \%$ among the $\geq 65$-year age group. Compared to the present study, a higher prevalence of cataract was also reported in studies done in Taiwan (15) and Indonesia (16). Both these studies used different diagnostic criteria and were carried out in different populations.
We found that the age group of 60 years and above, lower level of education and duration of diabetes mellitus of more than six years were statistically significant with cataract, after controlling for the confounding effects. Nanayakkara also reported (4) a statistically significant association between cataract and age more than 70 years. Several studies (13-14, 17-19) also reported that there was a significant increase in cataract with increasing age. Increasing age causes senile changes, which increase the lens opacities and the risk for cataract. Few studies had reported (11-19) that there was an association between lower level of education and cataract.

Present study did not reveal any statistically significant association between cataract and sex. Our findings are consistent with other studies $(4,19)$. In contrast, a study done in Korea reported a higher prevalence of cataract among females than in males (14). Another study reported that there was a significant association between cortical cataract and females, but not with other types of cataracts (18).

The present study reported there was no statically significant association between cataract and duration of alcohol consumption being more than 20 years. Mohan et al (20) also revealed no statistically significant association between cataract and the current alcohol consumption or with its duration.

In the present study, it was found that there was no significant association between cataract and the history of smoking or duration of smoking. Mohan et al too revealed that there was no statistically significant association between cataract and current smoking, duration of smoking or frequency of smoking (20). In contrast, a few studies reported a significant association between cataract and current smoking practice (4, 18-19). 
In the present study, it was found that there was no statically significant association between cataract and history of hypertension or duration of hypertension. In contrast, several studies $(4,16,18)$ reported a statistically significant association. Present study assessed the presence of hypertension by history, whereas the former studies have measured blood pressure. This is a limiting factor in the present study.

The present study reported no statistically significant association between cataract and history of diabetes mellitus. Our findings are consistent with findings of a few studies (18-19). The present study revealed a statistically significant association between cataract and duration of diabetes mellitus of more than six years. Some studies reported that there was statistically significant association between history of diabetes and cataract (4, 16-17). Different age groups considered in the two populations and the different diagnostic criteria used may be the reason for this. The present study assessed the presence of diabetes only by history, which was a limiting factor of the current study.

\section{Conclusions \& Recommendations}

In conclusion, even though the prevalence of visually impaired cataract in the better eye was low, the burden is likely to be significant due to impaired visual acuity. Being elderly, low income and longer duration of alcohol consumption were associated with cataract. The cataracts can be classified into cortical (anterior and posterior) and nuclear and posterior subcapsular. We recommend a community-based study to determine the prevalence of different sub-types of bilateral cataract and risk factors.

\section{Public health implications}

One of the main causes of visual impairment is cataract. The extent of visually impaired cataract in the better eye will affect the quality of life of a person. Therefore, necessary steps need to be taken to educate the vulnerable groups on the risk factors for early prevention of this condition.

\section{Author Declarations}

Competing interests: The authors declare that they have no competing interest.

Ethics approval and consent to participate: The Ethics Review Committee of the Faculty of Medicine, University of Kelaniya granted ethical clearance. It was informed that written consent was obtained from participants prior to data collection. Permission was obtained from the Regional Director of Health Services, Gampaha District.

Funding: Self-funded.

Acknowledgements: We would like to thank all the participants for the study and health authorities of Gampaha District, data collectors and members of the Board of Study in Community Medicine, Postgraduate Institute of Medicine.

Author contributions: $\mathrm{CH}$ participated in the design of the study, coordinated data collection, performed the statistical analysis and interpreted the data. CA participated in the design of the study, performed the statistical analysis, interpreted the data and drafted the first version of the manuscript. Both authors read and approved the final manuscript.

\section{References}

1. Pitts CR \& Tee Khaw P. A Textbook of Clinical Ophthalmology, Third Edition. Community Eye Health Journal 2003; 16(47): 47.

2. WHO. Universal Eye Health: a Global Action Plan 2014-2019. Geneva: World Health Organization, 2013.

3. WHO. Global Data on Visual Impairments 2010. WHO/NMH/PBD/12.01. Geneva: World Health Organization, 2012.

4. Nanayakkara SD. Vision related quality of life among elders in Gampaha District and associated risk factors for age related cataract. MD Thesis (Community Medicine). Colombo: Post Graduate Institute of Medicine, 2006.

5. Edussuriya K, Senanayake S, Senaratne T, Marshall T, Sullivan T, Selva D, Casson RJ. The prevalence and causes of visual impairment in Central Sri Lanka the Kandy Eye Study. Ophthalmology 2009; 116(1): $52-56$.

6. DCS. Census of Population and Housing Gampaha District. Colombo: Department of Census and Statistics, 2001. 
7. Jackson CRS \& Finlay RD. The eye in general practice ( $8^{\text {th }}$ edition). London: Churchill Livingstone, 1985.

8. Resnikoff S, Pascolini D, Mariottia SP, Pokharela GP. Global magnitude of visual impairment caused by uncorrected refractive errors. WHO Bulletin 2008; 86(1): 63-70.

9. Wadud Z, Kuper H, Polasck S, Lindfield R, Akm MR, Choudhurg KA, et al. Rapid assessment of avoidable blindness and needs assessment of cataract surgical services in Sathira District in Bangladesh. British Journal of Ophthalmology 2006; 90(10): 1225-1229.

10. Hashemi H, Yekta A, Jafarzadehpur E, Doostdar A, Ostadimoghaddam H, Khabazkhoob M. The prevalence of visual impairment and blindness in underserved rural areas: a crucial issue for future. Eye 2017; 31: 1221-1228.

11. Chua J, Lim B, Fenwick EK, Gan ATL, Tan AG, Lamoureux E, et al. Prevalence, risk factors and impact of undiagnosed visually significant cataract: the Singapore Epidemiology of Eye Diseases Study. PLoS ONE 2017; 12(1): e0170804.

12. Dandona R, Dandona L, Srinivas M, Giridhar P, Presad MN, Vilas K, McCarty CA, Rao GN. Moderate visual impairment in India: the Andhra Pradesh Eye Disease Study. British Journal of Ophthalmology 2002; 86 (4): 373-377.

13. Aarthi R, Roy G, Kar SS, Srinivasan R. Prevalence of cataract among adults above 50 years in a rural community of Villupuram, Tamil Nadu. International Journal of Advanced Medical and Health Research 2015; 2(1): 50-54.
14. Kim TN, Lee JE, Lee EJ, Won JC, Noh JH, et al. Prevalence of and factors associated with lens opacities in a Korean adult population with and without diabetes: The 2008-2009 Korea National Health and Nutrition Examination Survey. PLoS ONE 2014; 9(4): e94189.

15. Tsai SY, Hsu WM, Cheng CY, Liu JH, Chou P. Epidemiologic study of age-related cataracts among an elderly Chinese population in Shih-Pai, Taiwan. Ophthalmology 2003; 110(6): 1089-1095.

16. Husain R, Tong L, Fong A, et al. Prevalence of cataract in rural Indonesia. Ophthalmology 2005; 112(7): 1255-1262.

17. Vashist P, Talwar B, Gogoi M, Maraini G, Camparini M, Ravindran RD, et al. Prevalence of cataract in an older population in India: the India Study of Agerelated Eye Disease. Ophthalmology 2011; 118(2): 272-278.

18. Nirmalan KP, Robin LJ, Katz J, Tielsch JM, Thulasiraj RD, Krishnadas R, Ramakrishnan R. Risk factors for age related cataract in a rural population of Southern India: the Aravind Comprehensive Eye Study. British Journal of Ophthalmology 2004; 88(8): 989-994.

19. Leske CM, Chylack LT, Suh-Yuh Wu. The lens opacity case control study for risk factors for cataract. Archives of Ophthalmology 1991; 109(2): 244-251.

20. Mohan M \& Robert D. India-US case control study of age-related cataract. Archives of Ophthalmology 1989; 107(5): 670-676. 